\title{
Effects of cooling mode on properties of black ceramic pigments
}

\author{
Wu Liqing,Dong Weixia, Chen Zonglin, Luo Ting, Gu Xingyong* \\ Jingdezhen Ceramic Institute, Jingdezhen, 333001, P. R. China
}

\begin{abstract}
Keywords:black ceramic pigment, cooling mode, chemical stability
Abstract. The "iron-chromium-nickle-copper" black ceramic pigment was prepared without cobalt coloring agent using copper tailings and chromite waste residue replacement some of chromic oxide and iron oxide, etc. On the guaranteed of the performance unchanged, effects of cooling mode (i. e. quenching, rapid cooling and slow cooling) and soaking time on the color performance of black ceramic pigment were studied. The results showed that the change of black ceramic pigment was due to different cooling mode. When the sample is prepared at $1 \mathrm{~h}$ by the quenching mode, the obtained ceramic pigment has an optimum values for deep black hue $\left(\mathrm{L}^{*}=28.74\right)$, which has good chemical stability. It is suitable for daily and architectural ceramics decoration.
\end{abstract}

\section{Introduction}

Due to dignified, noble and elegant classic colors of the black ceramic products, it has attracted much attention. The black ceramic pigment is now widely used in the decoration of ceramics for daily use and construction [1] But at present, expensive $\mathrm{CoO}$ as a raw material is commonly used in the pure black pigment, which limits its mass production and application. Therefore, the development of low -price and cobalt- free black pigment has become one of the urgent problems. Now, the related researches about black ceramic pigment are carried out along the three directions: in order to improve the color stability of pigment, one is the study on modification of black ceramic pigment. The second is the preparation of the ceramic pigment using the industrial waste as raw material, to reduce production cost and increase the black pigment products. The last is the study of the new encapsulated carbon black pigment.

In the paper, free-cobalt black ceramic pigment was prepared using flotsam and chromium iron ore instead of part of the chromium and iron oxide by solid state reaction mode. On the guarantee of the performance unchanged, effects of process conditions i. g. cooling system and soaking time on the color performance of black ceramic pigment were studied.

\section{Experimental}

Chemical composition of copper tailings and chromite waste residue, as determined by X-Ray Fluorescence (XRF) were shown in Table 1 and Table 2. Other materials were chemical grade.

Black pigments were prepared by the traditional solid method. The black pigment composition was prepared by mixing $21.6 \%$ chromium oxide, $29.3 \%$ iron oxide, $16.6 \%$ nickel oxide, $14.2 \%$ copper oxide, $9.8 \%$ copper tailings and $8.5 \%$ chromite. To further characterize the color of black pigment, $5 \%$ black pigment $(\mathrm{C} 1)$ was added into barium base glaze. Batches were prepared by milling the constituents with water (1:2) for $30 \mathrm{~min}$, in a fast ball milling and using alumina balls as grinding media. The resultant slurry was sieved to by 250 meshes (sieve residue $<0.02 \%$ ). The glaze was used by dipping on the body. The resulting sample was fired at $1280{ }^{\circ} \mathrm{C}$ using electric box furnace 
Tab. 1 Major elements and their content of copper tailings

\begin{tabular}{|l|l|l|l|l|l|l|l|l|l|l|}
\hline Elements & $\mathrm{Cu}$ & $\mathrm{Au}$ & $\mathrm{Ag}$ & $\mathrm{As}$ & $\mathrm{Sb}$ & $\mathrm{Bi}$ & $\mathrm{Pb}$ & $\mathrm{Zn}$ & $\mathrm{Fe}$ & $\mathrm{Si}$ \\
\hline contents $(\%)$ & 0.44 & 0.4 & 6.3 & 0.28 & 0.14 & 0.01 & 0.43 & 1.58 & 43.31 & 29.05 \\
\hline
\end{tabular}

Tab. 2 Major elements and their content of chromite waste residue

\begin{tabular}{|l|l|l|l|l|l|l|l|l|l|}
\hline Elements & $\mathrm{Na}$ & $\mathrm{Al}$ & $\mathrm{Si}$ & $\mathrm{P}$ & $\mathrm{S}$ & $\mathrm{K}$ & $\mathrm{Ca}$ & $\mathrm{Ti}$ & $\mathrm{V}$ \\
\hline \multirow{3}{*}{ contents $(\%)$} & 0.086 & 2.55 & 10.511 & 0.036 & 0.062 & 0.345 & 0.182 & 0.278 & 0.17 \\
\cline { 2 - 10 } & $\mathrm{Cr}$ & $\mathrm{Mn}$ & $\mathrm{Fe}$ & $\mathrm{Co}$ & $\mathrm{Ni}$ & $\mathrm{Cl}$ & - & - & - \\
\cline { 2 - 10 } & 49.11 & 0.702 & 17.448 & 0.058 & 0.071 & 0.500 & - & - & - \\
\hline
\end{tabular}

Chemical compositions of raw materials were analysized by $\mathrm{X}$ ray fluorescence analyzer ((PANalytical B.V.). The crystalline phases were characterized by X-ray diffraction (XRD, German ). $L^{*} 、 a^{*} 、 b^{*}$ values were characterized by fully automatic whiteness meter in a WSD-3C instrument (Beijing Kang Guang instrument co., LTD). To investigate the chemical stability, 1 gram of the pigment powders were placed in $20 \mathrm{ml} \mathrm{HCl}$ aqueous solution $(25 \%)$ for $24 \mathrm{~h}$ at room temperature, and then the final pigment powders were washed for $4-5$ times and dried at $80{ }^{\circ} \mathrm{C}$.

\section{Results and discussion}
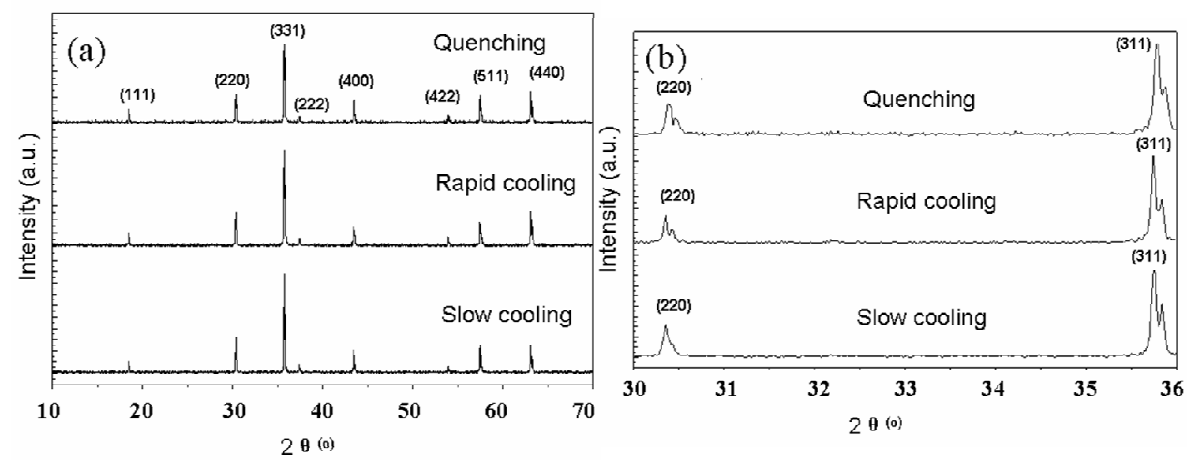

Fig. 1 XRD patterns of the samples synthesized at different cooling condition:Fig. 1 (b) is partial enlargement drawing of (220) and (311) peaks in Fig. 1(a)

Fig. 1 (a) shows XRD patterns of the samples synthesized at different cooling mode. Fig. 1 (b) shows the partial enlargement drawing of (220) and (311) peaks in Fig. 1(a). It can be seen that all the samples are composed of several different superposition characteristic peaks ( i. g. $\mathrm{NiFe}_{2} \mathrm{O}_{4}$ 、 $\mathrm{CuFe}_{2} \mathrm{O}_{4} 、 \mathrm{Cr}_{2} \mathrm{NiO}_{4}$ ), indicating that a variety of spinel maybe coexist. Compared to the sample prepared by slow cooling, the characteristic peaks of the samples via quenching and rapid cooling were broaden, suggesting that spinel crystallization degree of the sample prepared by quenching and rapid cooling is lower than that of the slow cooling.

Fig. 2 shows the effect of cooling mode on color performance (L, $\left.a^{*}, b^{*}\right)$ of the samples. For the samples after quenching, rapid cooling and slow cooling, the $\mathrm{L}^{*}$ values are 28.1, 27.1 and 27 , respectively. However, the change of $\mathrm{a}^{*}$ and $\mathrm{b}^{*}$ is the opposite. It is indicated that the sample has a deep black tone after quenching. As is well known, the color of the pigment is mainly determined by the transition metal cation coordination environment and coordination number. In the spinel crystal, a variety of transition metal ions will tend to occupy A and B position due to the action of thermal motion, if the energy difference of A and B position is not enough big, especially under the high temperature condition. In general, the entropy and the corresponding disorder degree increase 
with the temperature, and thus the transition metal cations will disorder the A and B distribution [2]. The samples are kept in a disorder distribution in the A and B position state of transition metal ions at high temperature after quenching treatment. For the slow cooling sample, the transition metal ions have enough time to occupy the thermodynamic equilibrium position. The disorder degree of the sample after quenching is between that of the samples after high temperature quenching and slow cooling, respectively. Therefore, the samples after the quenching and rapid cooling keep the disorder distribution of transition metal ions at high temperature. Transition metal ions such as F 5d orbitals split are diversified and strengthen the D-D transition probability [3], and thus the visible light absorption strengthens, so the blackness of the pigments enhances after quenching treatment. On the other hand, disordered distribution of transition metal ions deviate from the equilibrium position after quenching and rapid cooling process, which make lattice distortion increase (Fig. 3), thus the symmetry of the natural crystal lattice reduced, and further the asymmetry increased. Therefore, anharmonic effects of the lattice vibration and absorption of polar lattice vibration enhance [3], which make the black tone of the samples deepen due to the increase of visible absorption.

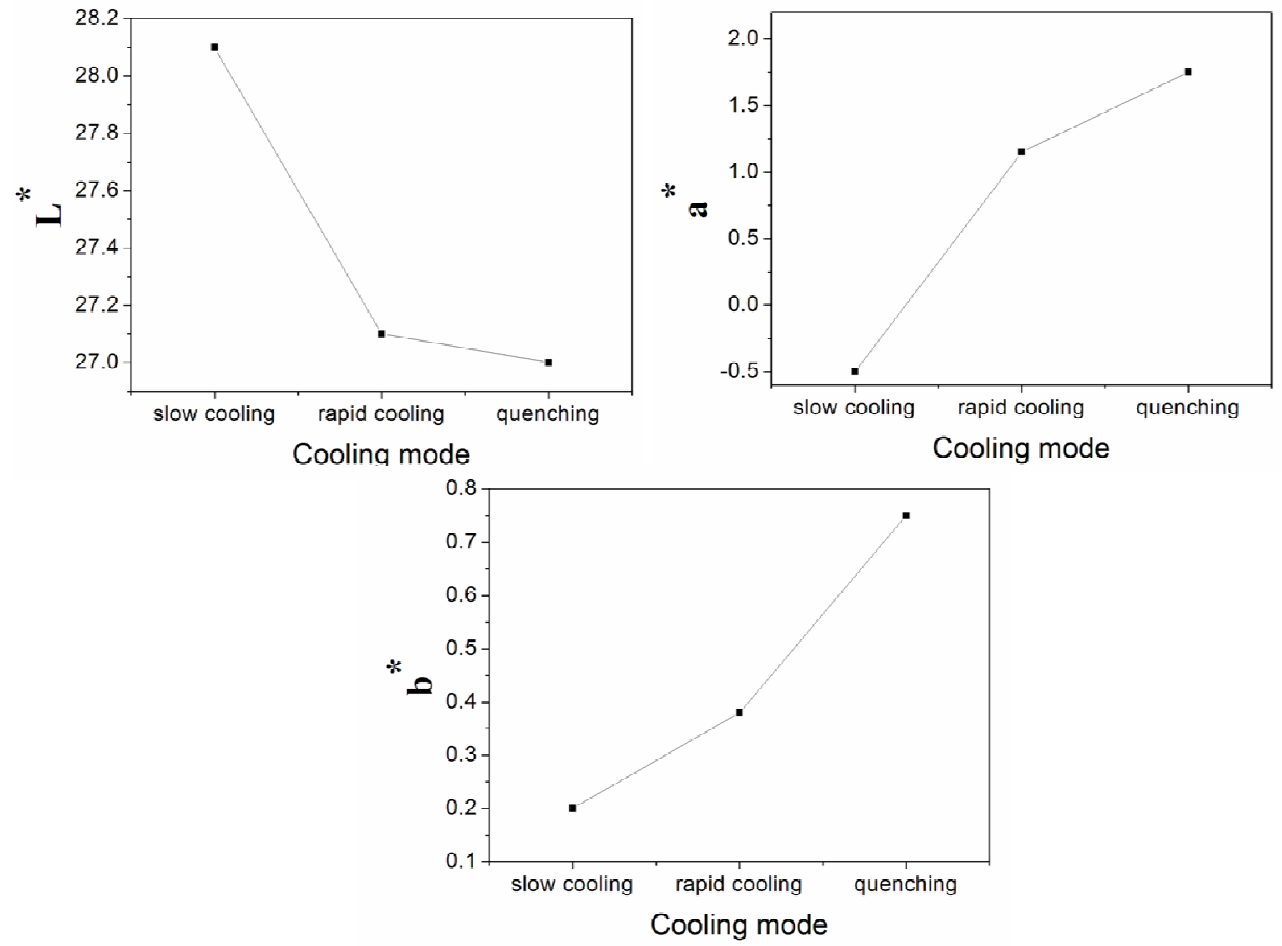

Fig. 2 The effect of cooling mode on color performance (L, $\left.a^{*}, b^{*}\right)$ of the samples

Fig. 3 shows the curves of lattice distortion and $\mathrm{L}^{*}$ of the sample $\mathrm{C} 1$ by different cooling mode using least square mode i. g. the Cauchy formula (1) to calculate by the XRD diffraction diagram of the spinel (Fig. 1) results.

$$
\frac{\beta \operatorname{COS} \theta}{\lambda}=\frac{1}{D_{h k l}}+4 E\left(\frac{\operatorname{Sin} \theta}{\lambda}\right)
$$

being $\beta$ the physical width of the peak of the corresponding diffraction angle (arc), $\lambda$ X-Ray wavelength, E distortion coefficient of crystal lattice, $D_{\text {hkl }}$ the crystal block size and $\theta$ grazing angle, respectively. 


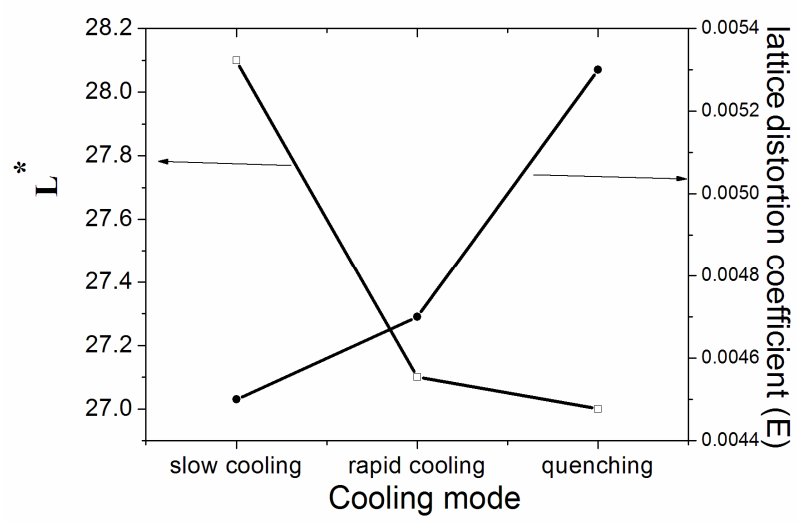

Fig. 3 The curves of lattice distortion coefficient $(\mathrm{E})$ and $\mathrm{L}^{*}$ of the sample $\mathrm{C} 1$ by different cooling mode

Table 3 shows the chroma data $\left(\mathrm{L}^{*}, \mathrm{a}^{*}, \mathrm{~b}^{*}\right)$ of the pigment by acid treated, the black pigment $\mathrm{C} 1$ is added to the barium base glaze at $1280^{\circ} \mathrm{C}$ for $15 \mathrm{~min}$. It can be seen that the pigment by acid treatment keeps almost unchanged, and glaze is applied on the body, the glaze after firing shows pure black, indicating the blackness tone is stable.

Table 3 The chroma data $\left(\mathrm{L}^{*}, \mathrm{a}^{*}, \mathrm{~b}^{*}\right)$ of the pigment by acid treated

\begin{tabular}{ccccc}
\hline Samples & $\mathrm{L}^{*}$ & $\mathrm{a}^{*}$ & $\mathrm{~b}^{*}$ & appearance \\
\hline $\mathrm{C} 1$ & 28.54 & -0.38 & 0.12 & black \\
Black glaze & 27.26 & -0.54 & 0.67 & black \\
\hline
\end{tabular}

\section{Conclusions}

In conclusions, the different cooling modes leads to a variation of black pigment color performance. For the samples prepared at quenching, rapid cooling and slow cooling, the $\mathrm{L}^{*}$ values are 28.1, 27.1 and 27 , respectively. It is mainly due to the different cooling modes which results in the transition metal ions distribution and the change of lattice distortion coefficient in the black pigment. After Quenching black ceramic pigment maintains the transition metal ions disorderly distribution at the high temperature. When the degree of disorder is bigger, lattice distortion coefficient increases, which makes visible light absorption strengthen, and displays the preferably black.

\section{Acknowledgements}

The present work was supported by the National Natural Science Foundation (Grant No. 51262014).

\section{References}

[1] T. Yu, The cobalt-free black pigment manufactured with PCB sludge and chromite, China Ceramic, 48(2012) 45-48.

[2] Z.Yang, Study of transition probabilities in transition in sodiumilike ions of Sc, Fe, Ni and Se, Chinese Journal of Atomic and Molecular Physics, 11(1994) 446-448.

[3] C. S. Richard, J. Lu, G. Beranger, et al. Study of $\mathrm{Cr}_{2} \mathrm{O}_{3}$ coating, Journal of Thermal Spray Technology, 4 (1995) 342-352. 